\title{
Research on the effectiveness of physical therapy in the treatment of LBP
}

\author{
Silişteanu Sînziana Călina, MD, Antonescu Elisabeta, Physicist, PhD \\ "Ştefan cel Mare” University, Suceava, "Lucian Blaga” University of Sibiu
}

\section{Introduction}

LBP management is complex and costly, with socio-economic and medical implications. Disabilities caused by painful back disorders represent a major problem of absenteeism from work (1). The prevalence of LBP in the active population (25-64 years old) is increasing.

There are studies (2) showing that between 60 and $80 \%$ of people may suffer from back pain during their lifetime and 5\% may present radiculopathy, the rest of them being diagnosed with nonspecific LBP. Of those, approximately $30 \%$ will be diagnosed with chronic LBP. More recent studies (3) show that the prevalence of LBP appearance for one year is of $65 \%$, for the entire life, it is of $84 \%$ and for present day, of 33\%. In the developed countries, 1 in 5 adults may experience symptoms of LBP, the number of these reaching $40 \%$ in England, Denmark, while in the US, the value is of 7-25\%. Approximately $80-90 \%$ of patients with LBP are diagnosed with "non-specific" low back pain and 3\% will require surgery. LBP is a common condition, representing 1/3 of rheumatic complaints. This condition interests both the young people and the adult one. Therefore, $25 \%$ of people aged between 30 and 50 years old consider LBP as the most frequent cause of work incapacity in the people below 45 years old.

Risk factors for the occurrence of LBP are: occupational (heavy physical work, lifting weights, torsional movement of the trunk, prolonged standing, sedentary lifestyle), psychological (depression, anxiety, fear of movement), socio-demographic characteristics (weight, age, incorrect posture, lifestyle, educational level, smoking, family problems, low incomes).

Medical rehabilitation in LBP involves combating pain and inflammation, improving statics and lumbosacral spine dynamics, improving paravertebral and abdominal muscle strength, gait rehabilitation. These objectives are achieved by pharmacological methods and physical-kinetic therapy.

The aim of the study was to emphasize the importance of physical therapy in the recovery of patients with low back pain, versus drug therapy or electrotherapy.

\section{Materials and methods.}

The current study was conducted over a period of 6 months within specialty ambulatory. For the study, there were included a number of 276 patients aged $25-80$ years old, divided into three groups: G1 received medical treatment (NSAIDs, analgesics, muscle relaxants, sedatives, vitamins of group B), group G2 followed electrotherapy and massage and G3 group received complex drug treatment, electrotherapy, massage, ultrasound treatment and physiotherapy.

Criteria for inclusion of patients in the three groups were: the consent given by them, age between 25 and 80 years old, the presence of painful and functional symptoms at spine lumbosacral level, possibility to assess the patients at the beginning and at the end of treatment. Exclusion criteria were: age $<25$ years old and $>80$ years old, decompensated associated diseases, debilitating disease, patients with low back pain of traumatic or tumour type, people who have not given their consent to participate in this study.

There were used analytical assessment tools (range of motion, muscle balance, body alignment, posture) and synthetic (VAS pain scale, LBP-Module scale, Quebec scale, quality 
of life evaluation index, Rotterdam index). The assessment was performed at the beginning of treatment and at 10 days after its completion.

VAS is a visual, subjective scale, in which the patient assesses pain at the beginning and the end of the recovery treatment. LBP-Module scale contains items related to work, leisure, physical activity, posture, pain and its intensity, depressed mood, irritability caused by pain, family activity. Quebec scale comprises items that refer to standing, sleep, physical activity, weight lifting, walking or driving, socioprofessional and family activity. Quality of life index was calculated based on the SF-36 scale and included items concerning the accomplishment of ADLs, ensuring sleep, active and passive recreation, resuming socioprofessional and family activities.

Distribution of patients per groups is found in the charts below:
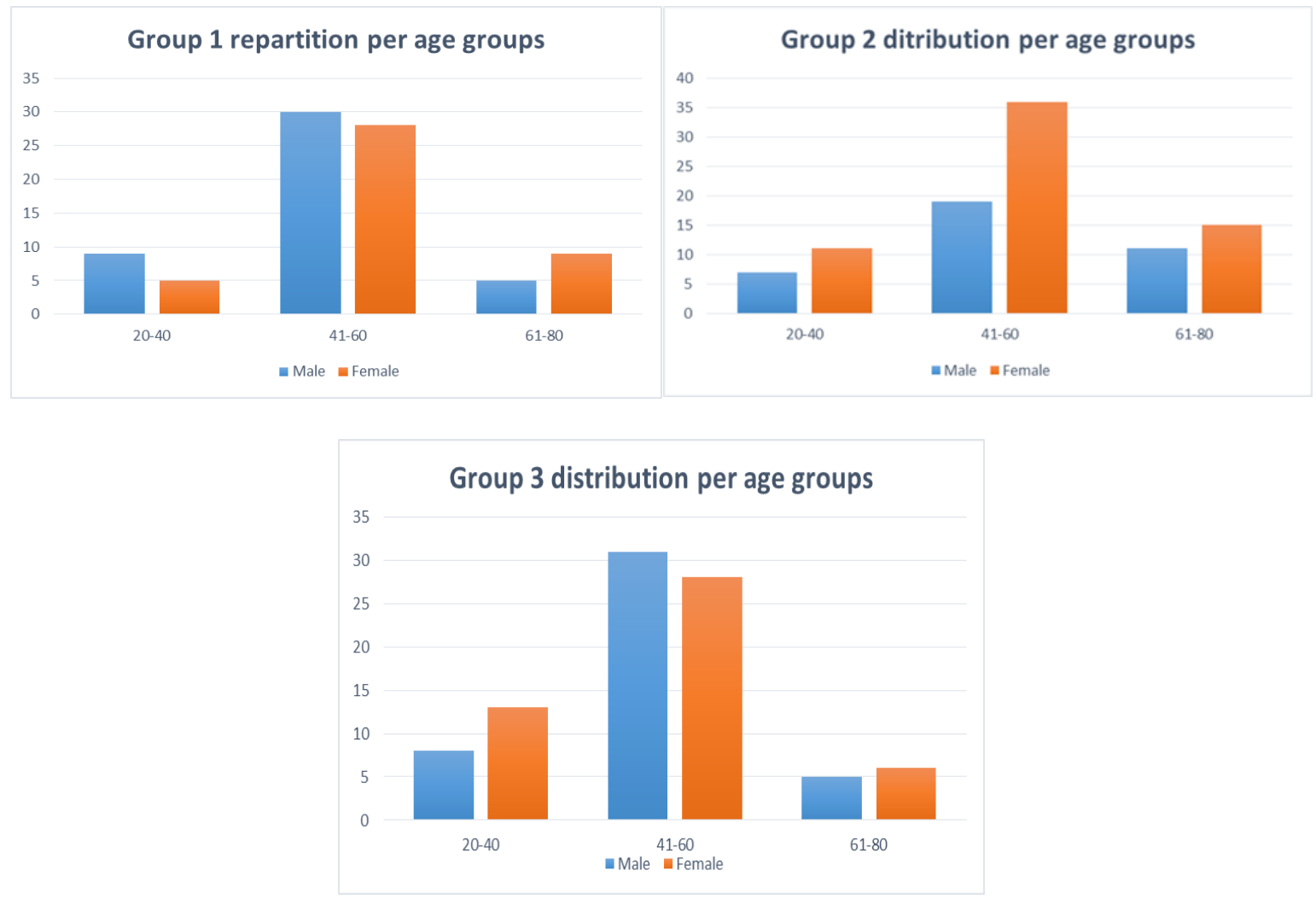

It can be seen that the most affected age group is the 41-60 years old group (active population) with 172 patients, followed by the age group of 20-40 years old with 53 patients and the age group of 61-80 years old with 51 patients.

Females were more affected by this condition than males. Thus, there was a total of 151 female patients, representing $54.71 \%$ and a total of 125 male patients, representing $45.29 \%$.

Electrotherapy procedures had analgesic role, muscle relaxation - diadynamic, especially on long term - biphasic, Trabert and TENS current.(4)
There was also used ultrasound therapy for its analgesic effect, muscle relaxation and hyperaemic effect. Ultrasounds are mechanical waves that propagate in an elastic environment with frequencies higher than $20 \mathrm{kHz}$. From the clinical point of view, there are studies showing that ultrasound is a safe technique, a form of non-ionizing energy, manageable and costeffective.(5) The average dose applied was 0.5 $\mathrm{W} / \mathrm{cm}^{2}$ and an exposure time of 5 minutes, with daily application.(6)

Massage procedures (smoothness, friction, vibration) were used for relieving pain 
and muscle relaxation. Reflexology massage, periosteal massage, pressure point massage (Cornelius nerve- points), Cyriax deep transverse massage were also used.

Physical therapy has the following objectives: reducing pain and paraspinal muscle contracture, lumbosacral spine restoring mobility, increasing muscular strength and endurance, restoring functional activity, relapse prevention.

There were applied: relaxation exercises ("hold-relax" type) by using Kabat diagonals (final positions), in order to influence the lower abdominal muscles as diagonal-rotational motion around the longitudinal axis of the segment induces the relaxation of the contracted muscle. Also, there were applied exercises for lumbosacral spine increased mobility (Williams), exercises to increase muscle strength (isotonic, isometric and isokinetic exercises). Asuplisation of the lumbar paravertebral muscles, hamstrings, iliopsoas muscles was intended, as well as the toning the abdominal and paravertebral muscles. Special attention was paid to correct posture, patient education, "back school" exercises. For $18 \%$, orthotics was needed, using lumbosacral orthoses. (7)

Statistical analysis - the following mathematical markers were used: the median, standard deviation and student $\mathrm{t}$ test.

\section{Results}

As it can be seen from the table and chart below, in group G1, there was a decrease of the values for median and standard deviation, for the initial and final moment.

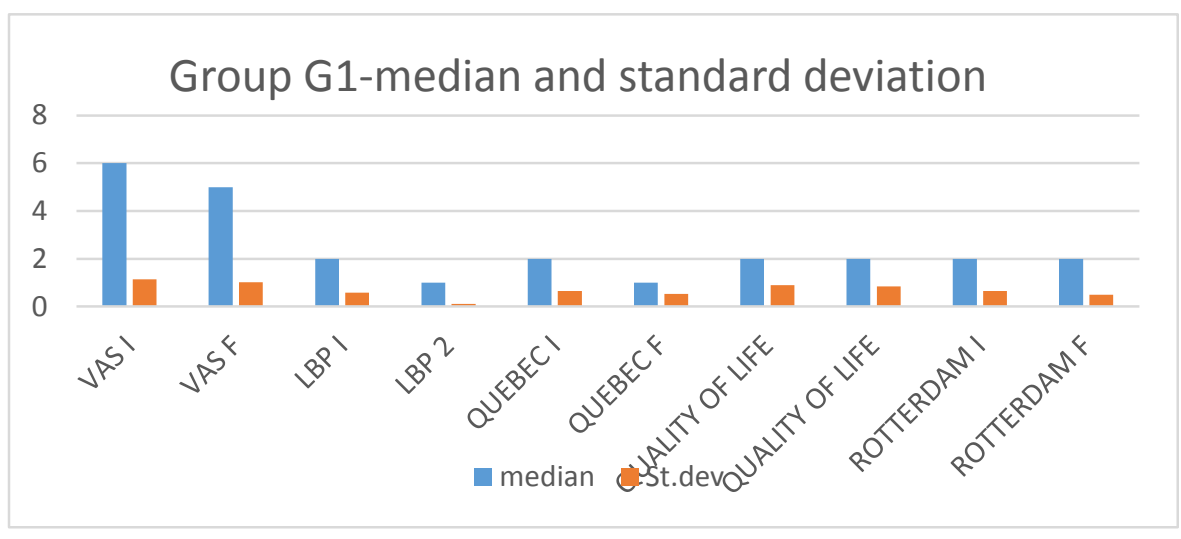

Student $\mathrm{t}$ test shows that for VAS scale and Rotterdam index, the values are statistically highly significant, and for the quality of life index, they are statistically extremely significant.

Group G1 - Student t test

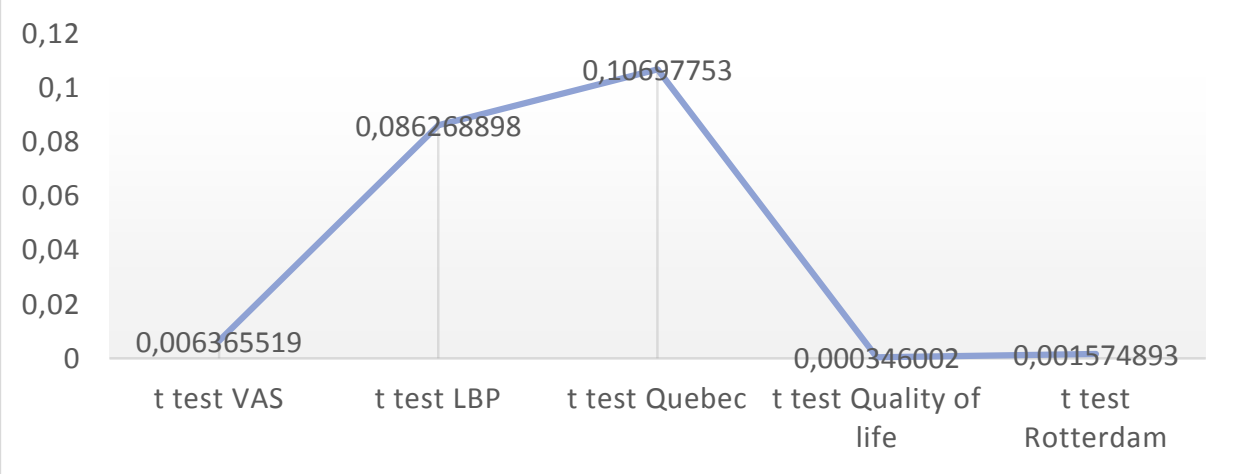


For group G2 as well, it was found that the deviation are lower compared to the initial final values obtained for median and standard moment.

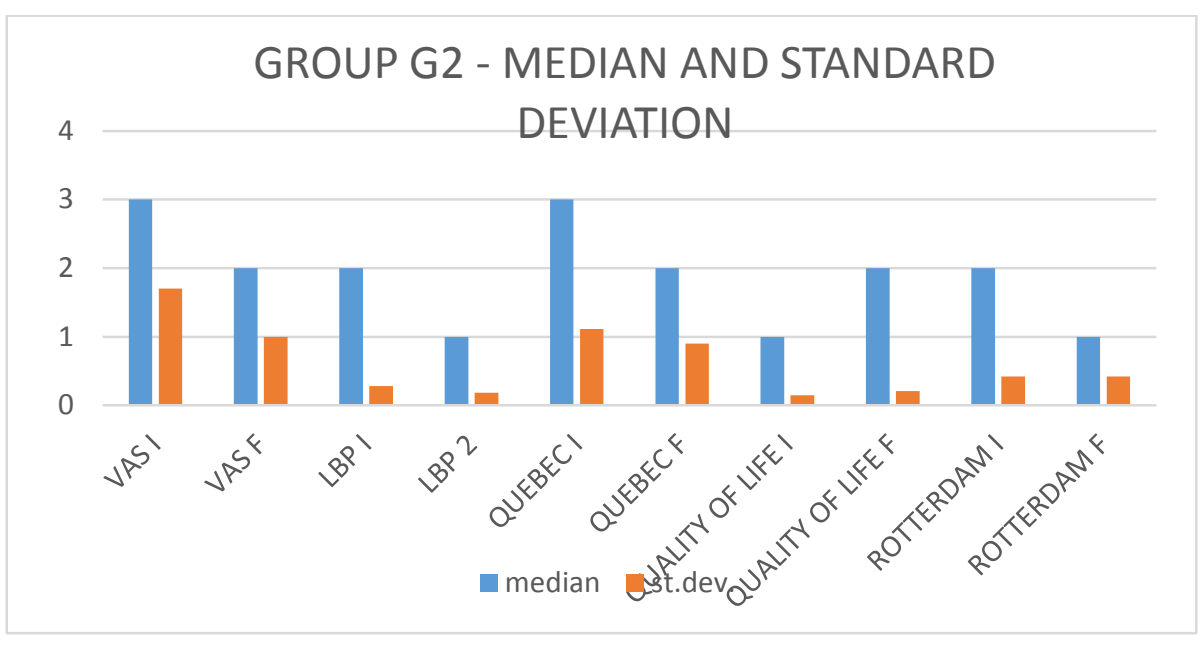

Student $\mathrm{t}$ test shows that for VAS and significant, and for other indicators, the values Quebec scales, the values are statistically are not significant.
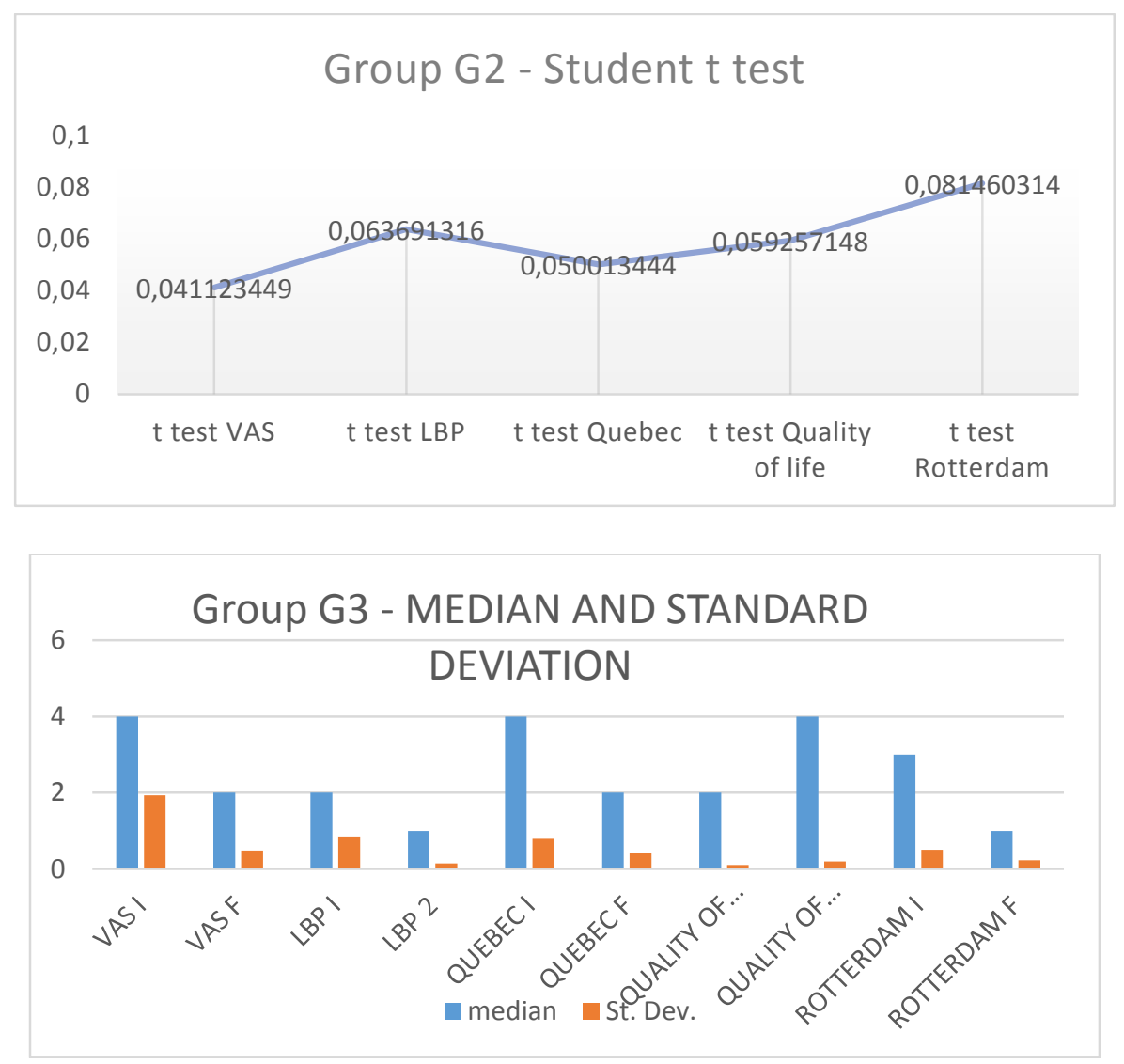

Group G3 has final values lower than baseline at all scales discussed. 


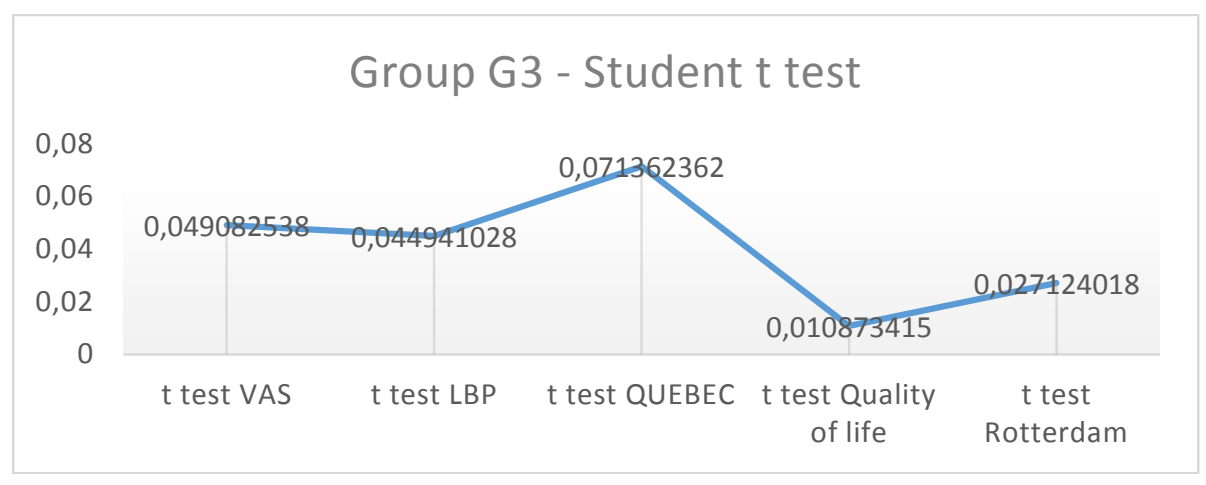

Student t test for group G3 shows that for VAS scale, LBP scale, quality of life index and the Rotterdam index, the values are statistically significant, for Quebec scale, the values are statistically significant and for Quebec test, the values are not significant.

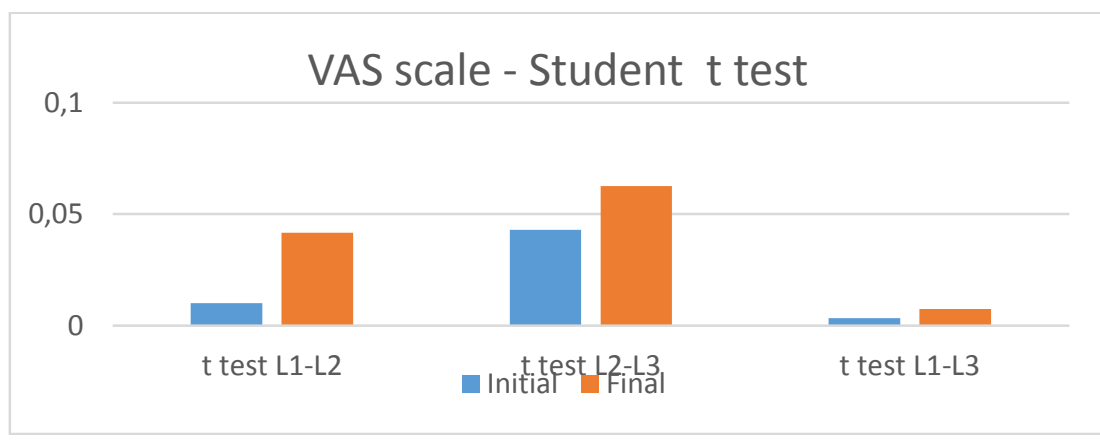

\begin{tabular}{|c|l|l|}
\hline $\begin{array}{l}\text { Student } \mathrm{t} \text { test/ } \\
\text { noment }\end{array}$ & Final \\
\hline $\mathrm{t}$ test G1-G2 & 0.01016628 & 0.041651281 \\
\hline $\mathrm{t}$ test G2-G3 & 0.04290741 & 0.062542207 \\
\hline $\mathrm{t}$ test G1-G3 & 0.00346317 & 0.007477223 \\
\hline
\end{tabular}

Comparison of results obtained for VAS scale in the three groups shows that the results are statistically highly significant for the initial and final moment for groups G1-G3, statistically significant for the initial and final moment for groups G1-G2 and for initial moment in groups G2-G3, and insignificant for the final moment in groups G2-G3. 


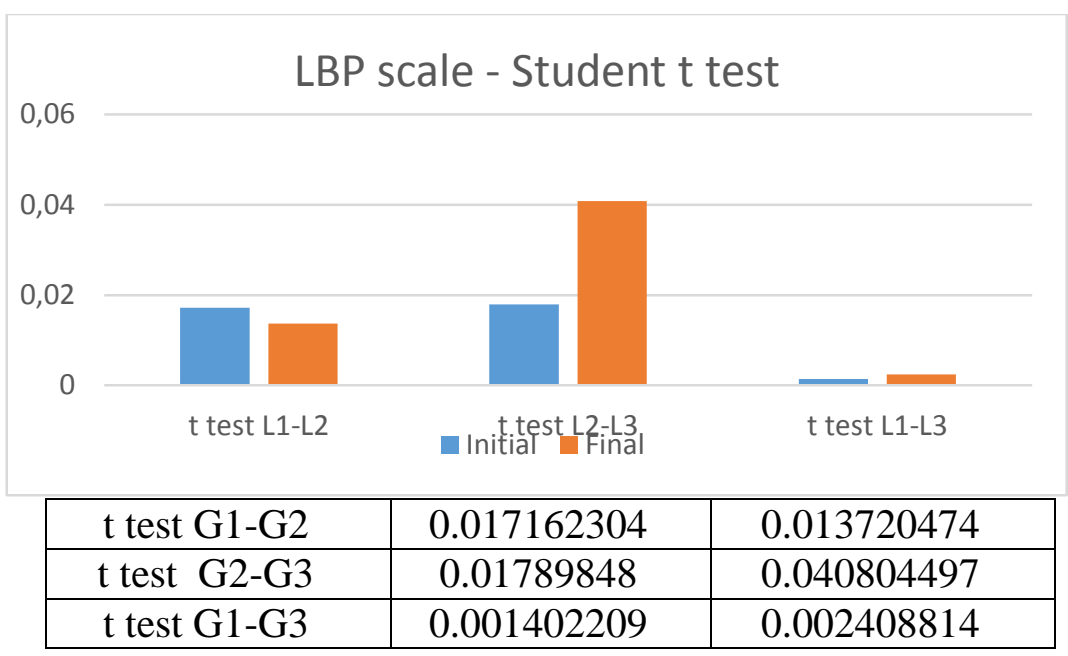

The results obtained for the LBP scale in all significant values for baseline and final moment three groups show statistically highly in all groups.

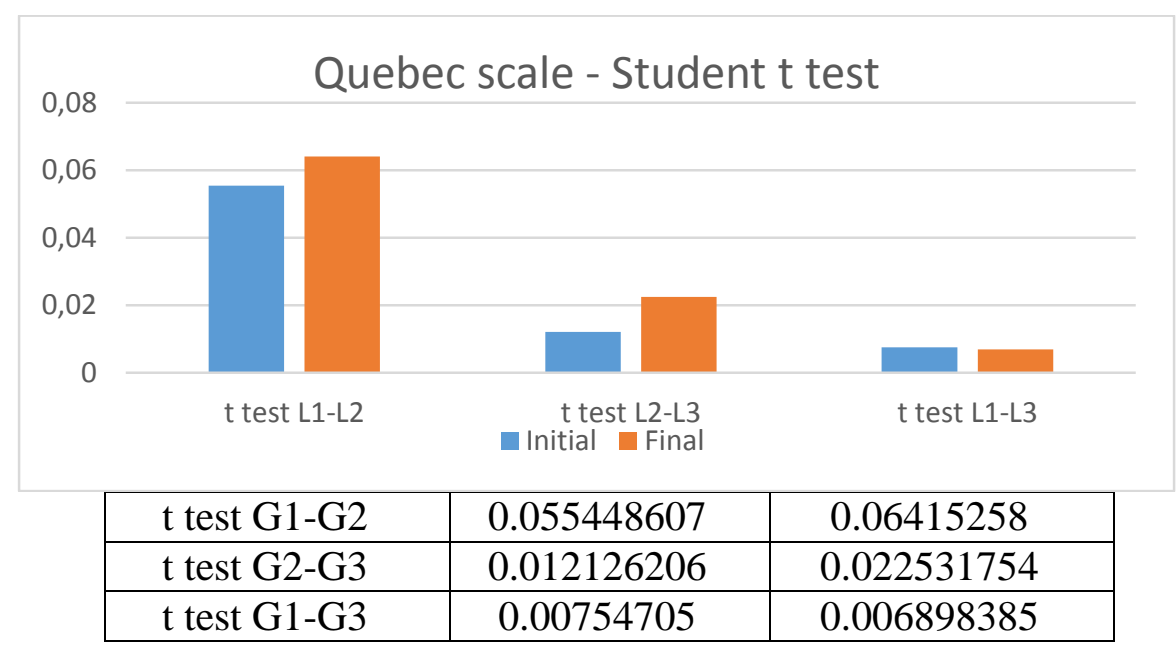

Comparison of results obtained for Quebec scale in the three groups shows statistically highly significant values for the initial and final significant for the initial and final moment for groups G2-G3 and not significant for the initial moment for groups G1-G3, statistically and final moment in groups G1-G2.

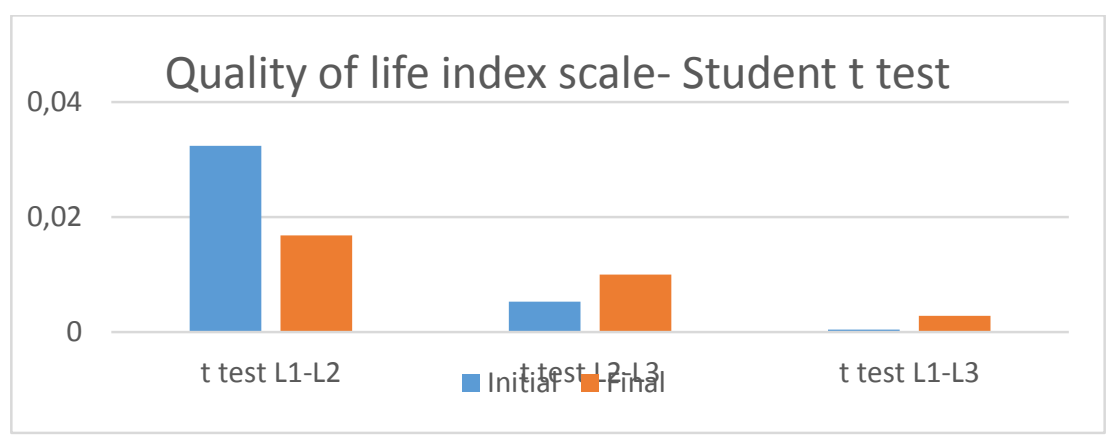




\begin{tabular}{|c|c|c|}
\hline $\mathrm{t}$ test G1-G2 & 0.032364589 & 0.016843722 \\
\hline $\mathrm{t}$ test G2-G3 & 0.005310203 & 0.01004065 \\
\hline $\mathrm{t}$ test G1-G3 & 0.000459702 & 0.002851587 \\
\hline
\end{tabular}

The results obtained for the quality of life index in the three groups shows that values are statistically highly significant for the initial moment in groups G1-G3, highly significant for baseline in groups G2-G3 and for final moment in groups G1-G3, and statistically significant for the initial and final moment in groups G1G2 and for final moment in G2-G3.

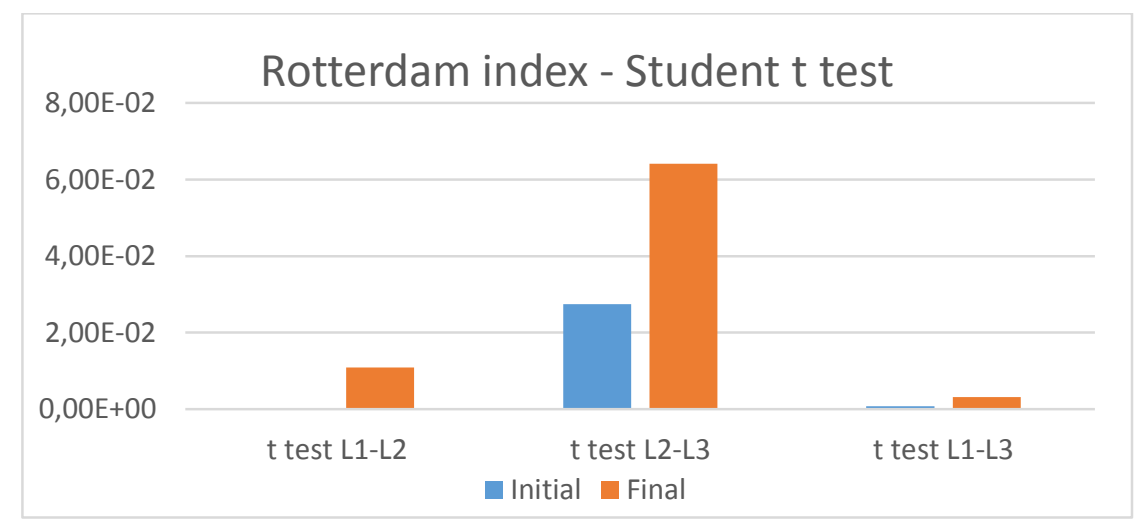

\begin{tabular}{|c|c|c|}
\hline$t$ test G1-G2 & $1.54403 \mathrm{E}-05$ & 0.010845548 \\
\hline $\mathrm{t}$ test $\mathrm{G} 2-\mathrm{G} 3$ & 0.027384822 & 0.064135927 \\
\hline $\mathrm{t}$ test G1-G3 & 0.000768872 & 0.003127785 \\
\hline
\end{tabular}

For Rotterdam scale in the three groups, there are highlighted values statistically extremely significant for the initial moment in groups G1-G3 and G1-G2, statistically highly significant for the final moment in groups G1-
G3, statistically significant for the initial moment in groups G2-G3 and final moment in groups G1-G2 and insignificant for the final moment in groups G2-G3.

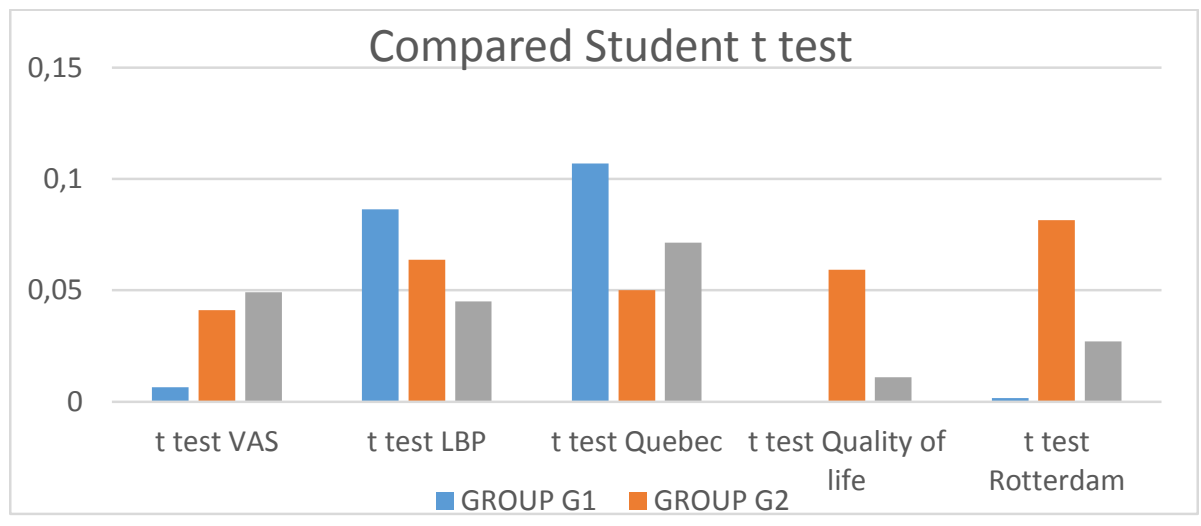

Comparative Student t-test for the three study groups shows statistically significant values for VAS scale, quality of life index, Rotterdam index.

\section{Conclusions}

After home-based treatment (medical) or ambulatory - rehabilitation unit (electrotherapy, 
massage, ultrasound and physiotherapy), it was found that the group G3 obtained statistically significant values for pain, quality of life index and clinical and functional status. It is noteworthy that the application of ultrasound and physical therapy improved pain and the functional indicators, as presented in the 20112012 Ebadi's study.

The complex treatment (medication, electrotherapy, massage therapy, ultrasound and physical therapy) reduces LBP relapses in the active population and provides the quick return to the professional activity, thus reducing absenteeism periods. Treatment should be individualized according to the patient, stage of disease and their professional activity.

\section{References:}

1. Van Tulder M.W. și Colab.-Outcome Of Non-Invasive Treatment Modalities On Back Pain:An Evidence-Based Review. Eur Spine J 15(Suppl):S64-81,2006

2. Wadell G. Şi Col.-Low Back Pain: A Twentieh Century Health Care Enigma. Spine 21:2820-5, 1996

3. Ebadi S., Ansari N.N., Naghdi S., Jalaie S., Sadat M., Fallah E.-The Effect Of Continuous Ultrasound On Chronic Non-Specific Lbp:A Single Blind Placebo-Controlled Randomized Trial.Bmc Musculoskeletal Disordes 2012,13:192

4. S.Poitras, L. Brosseau-Evidence Informed Management Of Chronic Lbp With Tens , Interferential Current, Electrical Muscle Stimulation, Ultrasound And Thermotherapy.The Spinal Journal 8(1):226233, 2008

5. Srbely J.Z., Dac D.C.-Ultrasound In The Management Of Osteoarthritis:Part I: A Review Of The Current Literature. J Can Chiropr Assoc 52(1): 30-37, 2008

6. Ebadi S., Henschken N., Ansari N.N., Fallah E.-Therapeutic Ultrasound For Chronic Lbp.Cochrane Database Syst Rev.2014;14:3
7. Van Tulder M.W-Conservative NonPharmacological Treatment For Chronic Lbp.Bmj 337:974, 2008

8. Antonescu Elisabeta, Silişteanu Sinziana - Study On The Influence Of Ultrasound Intensity In Chronic Back Pain Treatment, Acta Medica Transilvanica, V. Ii, No.2, 2012, Issn 1453-1968

9. Elisabeta Antonescu, Sinziana Calina Silisteanu, Clinical-Statistical Study On The Effectiveness Of Ultrasound Combined With Laser In Outpatient Treatment, Journal Of International Scientific Publications: Materials, Methods And Technologies Volume 8, Issn 1314-7269 (Online)

10. S.C. Silişteanu-Terapia Fizicală $\mathrm{Cu}$ Laser, Ultrasunete Şi Unde Scurte În Afecţiunile Dureroase Ale Coloanei Lombo-Sacrate, Editura Pim, 2014 